\title{
Gender Dimensions of Demographic Change in Pakistan
}

\author{
NAUSHIN MAHMOOD and DURR-E-NAYAB
}

\section{INTRODUCTION}

The achieving of equality and equity between men and women in different spheres of life is essential for the attainment of sustainable development goals. In this context, the need for enhancement of women's participation in national development programmes and their full integration into the development process has been widely recognised in various global and regional forums. More recently, the Programme of Action adopted by the International Conference on Population and Development at Cairo in 1994 reaffirmed and elaborated the role of women in national development, and endorsed a new strategy that emphasises "gender equality, equity and empowerment of women". In this context, the Programme of Action recommends that countries should act to empower women and should take steps to eliminate inequalities between men and women by providing them with more choices through expanded access to education and health services, skill development and employment, and eliminating all practices that discriminate against women [United Nations (1995)].

Pursuant to these principles, it is of interest to study the gender related aspects of population and development with a particular focus on the current situation and role of women in the family. While it is true that men are viewed as head of the family in almost all social structures who participate more in the formal economic and social affairs and decision making in the community, it is equally true that women tend to play a major role in household affairs, in forming production and consumption patterns and in generating income for the family. The "outside" role of men and their control over the resources empower them to have more influence in decision making within the household, whereas women's position within the household depends much more on her social and economic status, access to education, health care, job opportunities, etc. Recognising the importance of family as the basic social unit, women's role may be seen

Naushin Mahmood is Chief of Research and Durr-e-Nayab is Research Anthropologist at Pakistan Institute of Development Economics, Islamabad, respectively. 
as agents of change in many aspects of life including family formation, birth planning, the provision of education, health care and nurturing of children, the acquisition of an independent economic livelihood and maintenance of the household.

This paper examines the current situation of women and men in various aspects of family life in Pakistan and shows how the changing demographic and socio-economic conditions have contributed to benefit them over the past few decades. Of particular interest is an examination of demographic transition from a women in development perspective. More specifically, the study focuses on changes in such demographic parameters as age and sex structure, family formation, fertility, mortality, women's gains in education and their participation in the labour market as reflecting their relative role in the development process.

To begin with, Pakistan ranks among the lowest in the Asian region in many gender related human development indicators showing an index of 0.399 compared with .700 for Sri Lanka, .424 for India and .643 for Iran [UNDP (1998)].

Pakistan's female literacy rate is around 24 percent and for males about 50 percent. Women's participation in economic activity is only 16 percent and the share of their income is only 20 percent of the total. The maternal mortality rate is as high as 340 per 100,000 live births, total fertility rate is 5.3 children per woman and their share in top administrative and managerial jobs is merely 3 percent (Table 1). Besides, many existing laws/customs reflect discrimination against women at the family and societal level. This situation calls for a further assessment of an unequal distribution of familial and productive roles between women and men in Pakistan with its implications for development.

\section{DEMOGRAPHIC PERSPECTIVES}

\section{Age and Sex Structure}

Following the pattern of high population growth rate in the past, the age composition of both women and men is heavily weighted towards younger and unproductive ages. The proportion of population below 15 years of age is about 41 percent in the year 1998, 20 percent in case of females and 20.9 percent for males. With the recent decline in fertility, the share of the younger population has slightly declined, whereas the proportions in working age groups, especially 30 59 years have risen (Table 2). An important feature of the changing age structure of population is the gradual increase of women in total population from 46.2 percent in 1951 to 48 percent in 1998. This is an indication of a better coverage of female population in consecutive censuses and an improvement in their mortality overtime. 
Table 1

Gender-related Comparison of Some Indicators in Selected Countries, 1995

\begin{tabular}{lcccccc}
\hline Indicators & Pakistan & India & Bangladesh & Sri Lanka & Iran & Indonesia \\
\hline Gender Development Index (GDI) $^{\mathrm{a}}$ & 0.399 & 0.424 & 0.342 & 0.700 & 0.643 & 0.651 \\
$\quad \begin{array}{l}\text { Gender Empowerment Measure (GEM) } \\
\text { Life Expectancy at Birth }\end{array}$ & 0.179 & 0.228 & 0.305 & 0.286 & 0.261 & 0.365 \\
$\quad$ Female & 63.9 & 61.8 & 57.0 & 74.8 & 69.1 & 65.8 \\
$\quad$ Male & 61.8 & 61.4 & 56.9 & 70.3 & 67.9 & 62.2 \\
$\quad$ Adult Literacy (\%) & & & & & & \\
$\quad$ Female & 24.4 & 37.7 & 26.1 & 87.2 & 59.3 & 78.0 \\
$\quad$ Male & 50.0 & 65.5 & 49.4 & 93.4 & 77.7 & 89.6 \\
$\quad$ Gross Enrolment Ratio (\%) & & & & & & \\
$\quad$ Female & 27.0 & 46.5 & 30.9 & 67.9 & 62.6 & 59.1 \\
$\quad$ Male & 53.1 & 60.1 & 39.6 & 64.7 & 67.0 & 61.3 \\
$\quad$ Share of Income (\%) & & & & & & \\
$\quad$ Female & 20.6 & 25.4 & 23.1 & 35.5 & 18.9 & 33.0 \\
$\quad$ Male & 79.4 & 74.6 & 76.9 & 64.5 & 81.1 & 67.0 \\
$\quad \begin{array}{l}\text { Maternal Mortality Rate per 100,000 } \\
\quad \text { Births (1990) }\end{array}$ & 340.0 & 570.0 & 850.0 & 140.0 & 120.0 & 650.0 \\
$\quad \begin{array}{l}\text { Total Fertility Rate } \\
\text { Contraception Prevalence Rate }\end{array}$ & 18.3 & 3.2 & 3.3 & 2.2 & 5.0 & 2.8 \\
$\quad$ Seats Held by Women in Parliament - & & 41.0 & 49.0 & 66.0 & 65.0 & 55.0 \\
$\quad$ 1997 (\%) & 2.6 & 7.3 & 9.1 & 5.3 & 4.9 & 11.4 \\
\hline
\end{tabular}

Source: Human Development Report 1998, UNDP.

Note: a GDI- Index including adult literacy, gross enrolment ratio and share of total income.

${ }^{\mathrm{b}} \mathrm{GEM}$-Index including seats in parliament, employment in administrative and managerial positions, employed as professionals and technical workers and share in total income.

Table 2

Distribution of Population by Broad Age Group and Respective Sex Ratios: Pakistan: 1951-1998

\begin{tabular}{|c|c|c|c|c|c|c|c|c|c|c|}
\hline \multirow[b]{2}{*}{ Year } & \multicolumn{2}{|c|}{ 0-14 Years } & \multicolumn{2}{|c|}{ 15-29 Years } & \multicolumn{2}{|c|}{ 30-59 Years } & \multicolumn{2}{|c|}{60 and above } & \multicolumn{2}{|c|}{ Total } \\
\hline & Female & Male & Female & Male & Female & Male & Female & Male & Female & Male \\
\hline \multicolumn{11}{|c|}{ Population Distribution (\%) } \\
\hline 1951 & 20.4 & 22.7 & 12.3 & 14.3 & 10.7 & 13.9 & 2.6 & 3.1 & 46.2 & 53.8 \\
\hline 1961 & 20.0 & 22.4 & 11.5 & 13.0 & 11.9 & 14.2 & 3.0 & 4.0 & 46.5 & 53.5 \\
\hline 1972 & 20.7 & 23.1 & 10.9 & 12.3 & 11.9 & 14.0 & 2.9 & 4.1 & 46.7 & 53.2 \\
\hline 1981 & 21.5 & 23.0 & 11.2 & 12.6 & 11.9 & 12.8 & 3.0 & 4.0 & 47.5 & 52.5 \\
\hline 1998 & 20.0 & 20.9 & 12.4 & 13.2 & 13.3 & 14.5 & 2.8 & 3.1 & 48.0 & 52.0 \\
\hline \multicolumn{11}{|c|}{ Sex Ratios (Females per 100 Males) } \\
\hline 1951 & 89.9 & & 86.0 & & 76.9 & & 83.9 & & 85.9 & \\
\hline 1961 & 89.3 & & 88.5 & & 83.8 & & 75.0 & & 86.8 & \\
\hline 1972 & 89.6 & & 88.6 & & 85.0 & & 70.7 & & 87.7 & \\
\hline 1981 & 93.5 & & 88.9 & & 93.0 & & 75.0 & & 90.5 & \\
\hline 1998 & 95.7 & & 93.9 & & 91.7 & & 90.3 & & 92.5 & \\
\hline
\end{tabular}


Another way of observing women's contribution to population changes is the improvement in sex ratios as measured by the number of females over 100 males. Overall, the sex ratio was 86 (women as per 100 men) in 1951 which increased to 90.5 in 1981 and 92.5 in 1998 (Table 2). A progressive change in sex ratios is observed in all age groups particularly in the working age population from 76.9 percent in 1951 to 91.7 in 1998. This is, of course, a result of changes in various demographic parameters such as fertility, mortality and migration, which are closely related to women's and men's role in society. An increase in sex ratios of young and working age group (15-59 years) is mainly a result of male out migration during the 70s and 80s. Improvement in mortality of females is another factor contributing to increased female population and the respective sex ratios.

\section{Household Formation}

The household life cycle is generally considered to begin with marriage of a couple and ends with the death of the last surviving spouse. Marriage, particularly timing of first marriage, is an indicator of women's exposure to childbearing and the beginning of family formation. In Pakistan, where the legal limitation on age at marriage is 16 years for women and 18 years for men, many parents are still known to marry off their daughters at an early age, particularly in rural areas and in poor sections of society. As the development process has progressed and access to educational opportunities and exposure to urban and modern living have increased, chances of increase in age at marriage have also risen. The data from censuses indicate that between the years 1951 and 1998, the singulate mean age at marriage (SMAM) has gradually increased from about 17 years to 22 years for females and from about 22 years to 26.5 years for males. The change in age at marriage has been greater for women than men resulting in a reduction in age difference of spouses from 5.4 years in 1951 to 4.5 years in 1997 (Table 3). Delayed marriage, to some extent, reflects social and economic progress that

Table 3

Changes in Singulate Mean Age at Marriage

\begin{tabular}{lccc}
\hline Year & Female & Male & Difference (Male-Female) \\
\hline 1951 & 16.9 & 22.3 & 5.4 \\
1961 & 18.1 & 23.6 & 5.5 \\
1972 & 19.8 & 24.9 & 5.1 \\
1981 & 20.7 & 25.0 & 4.3 \\
1991 & 21.6 & 26.3 & 4.7 \\
1997 & 22.0 & 26.5 & 4.5 \\
\hline
\end{tabular}

Source: Pakistan Fertility and Family Planning Survey 1996-97, National Institute of Population Studies. 
eventually affects women status and reduces the gender gap in many indicators. High female age at marriage is also stated to be associated with female autonomy and has a negative effect on fertility [Abadian (1996) and Sathar (1996)].

Increase in age at marriage is supported by the continued increase in proportion never married of both women and men in younger age groups. For example, in the 15-19 age group, never married females increased from 46.6 percent in 1961 to almost 83 percent in 1996-97. Compared with this, the percentage for males increased from 83.7 to 96.2 over the same period. Among 20-24 years old, the proportion of single females also rose substantially from only 12 percent 1961 to 41 percent in 1996-97, whereas corresponding percentage for males increased from 52.9 to 75.5 (Table 4). These trends are clearly pointing out that increased chances for education and employment opportunities for women and the related social change tend to make marriage postponement an acceptable or even a desirable option for young women and men.

Table 4

Proportion of Never-Married Population (15 years and above)

by Age and Sex: Pakistan: 1961 to 1996-97

\begin{tabular}{|c|c|c|c|c|c|c|c|c|c|c|}
\hline \multirow[b]{2}{*}{ Year } & \multicolumn{2}{|c|}{ 15-19 } & \multicolumn{2}{|c|}{$20-24$} & \multicolumn{2}{|c|}{ 25-29 } & \multicolumn{2}{|c|}{$30-34$} & \multicolumn{2}{|c|}{35 and above } \\
\hline & Female & Male & Female & Male & Female & Male & Female & Male & Female & Male \\
\hline 1961 & 46.6 & 83.7 & 12.0 & 52.9 & 5.1 & 27.9 & 3.0 & 14.2 & 11.0 & 31.0 \\
\hline 1981 & 70.6 & 92.5 & 26.5 & 64.6 & 8.7 & 31.3 & 3.9 & 13.9 & 10.2 & 20.48 \\
\hline 1996-97 & 82.9 & 96.2 & 41.0 & 75.5 & 13.6 & 38.7 & 3.2 & 14.7 & 7.9 & 15.8 \\
\hline
\end{tabular}

Source: Census of Pakistan 1961, 1981, Statistics Division, Government of Pakistan.

Pakistan Fertility and Family Planning Survey 1996-97, National Institute of Population Studies.

\section{Household Size and Structure}

The number of households in Pakistan has been continuously increasing due to growth of population and formation of new families with no notable change in household size overtime. The 1998 Population and Housing Census shows an average household size of 6.6 persons and more than 50 percent of households consist of six or more persons [FBS (1998)].

The gender related aspects of household composition in Pakistan clearly show the prominence of men as more than 90 percent of households are headed by men. Data from various surveys between the year 1990-91 to 1997-98, however, reveal that the percentage of households headed by men has slightly decreased from 93.8 to 91.5 , and consequently women headed households have increased from 6.2 percent to 8.5 percent (Table 5). It is generally viewed that the small percentage of female headed households is likely to be an underestimate given the gender biases of both enumerators and respondents in reporting women as household heads. In the socio-cultural context of Pakistan and in terms of relatively low status and autonomy of women in the household, 
Table 5

Composition of Household Heads by Sex and Marital Status

\begin{tabular}{|c|c|c|c|c|c|}
\hline \multirow[b]{2}{*}{ Year and Sex } & \multirow{2}{*}{$\begin{array}{c}\text { Total No. of } \\
\text { Households }(000)\end{array}$} & \multirow{2}{*}{$\begin{array}{c}\text { Household } \\
\text { Headship (\%) }\end{array}$} & \multicolumn{3}{|c|}{ Marital Status (\%) } \\
\hline & & & Single & Married & Widowed/Divorced \\
\hline 1990-91 & 16,509 & & & & \\
\hline Female & & 6.2 & 0.1 & 3.8 & 2.3 \\
\hline Male & & 93.8 & 3.7 & 85.6 & 4.5 \\
\hline 1996-97 & 18,956 & & & & \\
\hline Female & & 8.0 & 0.1 & 4.5 & 3.3 \\
\hline Male & & 92.0 & 3.9 & 83.5 & 4.8 \\
\hline $1997-98$ & 19,701 & & & & \\
\hline Female & & 8.5 & - & - & - \\
\hline Male & & 91.5 & - & - & - \\
\hline
\end{tabular}

Source: Adapted from Compendium on Gender Statistics Pakistan, 1998, Federal Bureau of Statistics.

they are generally not reported as heads of the family, even where women are the sole source of economic support. Women are usually counted as household heads where they are living alone or have no adult male in the household [FBS (1998)].

Besides these finding from national surveys, evidence from an intensive study carried out in the city of Karachi indicates 10 percent of the households headed by women who are mostly wives of male migrants divorces/widows, and wives of nonearning husbands. Women heads belonging to latter two groups are from the poorest sections in Karachi and have only one-fourth of an average monthly income of that of male-headed households [Pakistan (1995)], indicating the disadvantaged position of women in maintaining the households. The findings from a small sample study on the elderly population (60+) in some rural and urban locations in Punjab and NWFP show that the lower proportions of female household headship is indicative of relatively higher dependency of females on other males, especially their sons [Afzal (1998)].

Household headed by women are clearly associated with their age and changing marital status. Single women and men who are more likely to be young are hardly reported as household heads - the percentage is less than one percent for women and 3.9 percent for men in the year 1996-97. As women become older, the probability of widowhood associated with being household head rises. Evidence from the 1996-97 Pakistan Integrated Household Survey shows that the proportion of female headed households among widowed has increased to 3.3 percent compared with 4.8 percent for males, indicating a small difference in headship status between women and men during widowhood. In contrast, a high proportion of household heads is of married men (85 percent) compared with only 4.5 percent for married women (Table 5).

As a result of changing socio-economic conditions, patterns of family structure are shifting towards nuclear family system in Pakistan. The 1996-97 PIHS shows 59 
percent of households as nuclear against 41 percent as extended households. Among the only 8 percent households headed by women, about 5 percent are nuclear family and only 3 percent are extended households compared with 55 percent and 30 percent respectively, in case of male headed households. Hence, wide gender differences are evident in headship status by age, sex and marital status. It appears that even the solely elderly and widowed women are ignored to be declared as household heads as the male members are considered responsible for household affairs and major decision-making in the family.

\section{Reproductive Behaviour}

Achievement of low fertility and small family size is an outcome of change in the reproductive behaviour of women reflecting women's role in birth planning. Unlike the experience of many other populations in the Asian region, fertility transition in Pakistan has occurred in a relatively long period of time as total fertility remained above six births per woman for almost three decades. Recent demographic surveys, however, point towards a decline in fertility since the 1990s. The total fertility rate fell from 6.27 births per woman in 1970-75 to 5.26 in 1992-96 (Table 6). As a part of the process of fertility transition, women of all ages have shown fewer births, but the decline is more obvious and consistent among older women aged 35 years and above. During 1975 to 1995, agespecific fertility declined from 104 to 44 births per 1000 women among 15-19 years old, from 266 to 227 births among 20-24 years old and from 204 to 145 births per 1000 women among 35-39 years old. (Table 6). For young and teenage women who are increasingly better educated, decline in fertility rate is attributed to increase in age at marriage, while the decline in fertility of older women is consistent with higher contraceptive use among those women.

Table 6

Age-Specific Fertility Rates and Total Fertility Rates

\begin{tabular}{lccccc}
\hline Ages & PFS & PCPS & PDHS & PCPS & PFFPS \\
(Years) & 1975 & $1984-85$ & $1990-91$ & $1994-95$ & $1996-97$ \\
\hline $15-19$ & 104 & 64 & 84 & 44 & 82 \\
$20-24$ & 266 & 223 & 230 & 227 & 245 \\
$25-29$ & 314 & 263 & 268 & 307 & 275 \\
$30-34$ & 264 & 234 & 229 & 243 & 212 \\
$35-39$ & 204 & 209 & 147 & 179 & 145 \\
$40-44$ & 93 & 127 & 73 & 92 & 71 \\
$45-49$ & 8 & 71 & 40 & 36 & 23 \\
TFR & 6.27 & 5.95 & 5.40 & 5.64 & 5.26 \\
\hline
\end{tabular}

Sources: Pakistan Fertility Survey (PFS) 1974, Population Welfare Division, Government of Pakistan. Pakistan Demographic and Health Survey (PDHS)1990-91, National Institute of Population Studies. Pakistan Contraception Prevalence Survey (PCPS) 1984-85, 1994-95, Ministry of Population Welfare, Government of Pakistan.

Pakistan Fertility and Family Planning Survey (PFFPS) 1996-97, National Institute of Population Studies. 
The observed decline in fertility is closely related to changes in the desired and ideal family size which are reflective of an attitudinal change among couples that can ultimately affect their reproductive behaviour. The available evidence suggests a systematic decline in ideal family size from 4.9 children in 1984-85 to 4.1 in 1990-91 and to 3.6 in 1994-95 (PCPS, 1994-95). Numerous fertility surveys also indicate that both women and men are increasingly expressing the desire not to have any more children or delay the next birth. About 40 percent of wives and 30 percent of husbands have reported no desire for more births in the PDHS of 1990-91 among a sample of 1260 matched couples [Mahmood and Ringheim (1997)]. Son preference partially accounts for the persistence of the desire for more births. Many women with three or more surviving children still desire more births in the hope of having a son and son preference is strongly related with contraceptive use among couples [Mahmood (1996)]. Research evidence shows that husband's desire for children is more important in increasing the likelihood of contraceptive use, and strong husband's attitudes towards fertility and family planning suggest greater focus on men in promoting use rate and altering the reproductive behaviour of couples [Mahmood and Ringheim (1997)].

Efforts to lower fertility by family planning programme in Pakistan were formally established in 1965. Until the beginning of 1990s, the programme could not claim rapid rises in contraceptive prevalence rates as the percentage using contraceptive was only 11.8 in 1990-91. It showed a significant increase to 24 percent in the year 1996-97 with 7 percent (i.e. about 30 percent of total current use) contributed by traditional methods. (Table 7). Thus, the output of the programme can be claimed to go beyond family planning and non-programme factors in recent years.

Table 7

Current Use of Contraception, and the Method Used

\begin{tabular}{lcrrr}
\hline & PCPS 1984-85 & PDHS 1990-91 & PCPS 1994-95 & PFFPS 1996-97 \\
\hline Contraception Prevalence Rate (\%) & & & & \\
Any Method & 9.1 & 11.8 & 17.8 & 23.9 \\
Any Modern Method & 7.6 & 9.0 & 12.6 & 16.9 \\
Any Traditional Method & 1.5 & 2.8 & 5.2 & 7.0 \\
Method Used (\%) & & & & \\
Pill & 1.4 & 0.7 & 0.7 & 1.6 \\
IUD & 0.8 & 1.3 & 2.1 & 3.4 \\
Injectables & 0.6 & 0.8 & 1.0 & 1.4 \\
Vaginal Methods & 0.1 & 0.0 & 0.0 & 0.1 \\
Female Sterilisation & 2.6 & 3.5 & 5.0 & 6.0 \\
Condom & 2.1 & 2.7 & 3.7 & 4.2 \\
Withdrawal & 0.9 & 1.2 & 4.2 & 4.6 \\
\hline
\end{tabular}

Source: Same as Table 6. 
As elsewhere, national family planning programme in Pakistan is extremely female biased, where women have simply been the objects and targets of the programme. Male contraceptives, account for only 4.2 percent of modern methods and 4.6 percent of traditional methods among current users in the year 1996-97 (Table 7). Thus recent fertility decline in Pakistan has largely been attributed to increases in contraceptive use with major contribution by women users.

Despite the recent marked increase in contraceptive use, unmet need for family planning remains high among Pakistani couples. In 1996-97, about 37.5 percent of currently married women do not want another child and are not using any method indicating large unmet need for family planning [NIPS (1998)]. The most commonly cited factors considered as obstacles to the use of birth planning among women are their perceptions about husband's disapproval; fear of side effects; and the socio-cultural and religious taboos about birth control [Population Council (1997)]. These factors and the influence of husbands in decision-making restrains many women to use contraception even if they wish to avoid pregnancy. Given the evidence of little or no communication between husbands and wives on family planning matters and the unequal balance of power in gender relations within the household, women are deterred to implement their reproductive goals [NIPS (1988); Sathar and Kazi (1997)], thereby resulting in unwanted births and delaying the process of fertility decline in Pakistan.

\section{Mortality and Health}

Closely related to changes in fertility and socio-economic conditions is the decline in mortality. While achievements in fertility decline have been slow, mortality fell steadily and more consistently beginning in the 1950s. Although estimates of infant mortality vary by source, it is reported to have declined substantially from 140 in 1970 to about 104 per 1000 live-births in 1990 [United Nations (1998)]. The Pakistan Demographic Survey (PDS) results show an infant mortality rate of 127 for 1984 which fell markedly to 104 in 1987 and 102 per 1000 live births in 1995. As part of the biological process, female infant mortality is generally lower than male infant mortality. Based on the 1990-91 Pakistan Demographic and Health Survey estimates, infant mortality among females is about 95 compared with 101 per 1000 live births for males during 1980-85. It further declined to 79.7 for females and 98.5 for males during 198691 (Table 8). As in South Asia, Pakistan has a unique case of excess girls' child mortality between ages of 1-4 years, indicating a survival disadvantage for girl child. The evidence shows that female mortality at that age exceeds male mortality by 67 percent in Pakistan [Arnold (1996)].

Reductions in mortality have led to substantial improvements in expectation of life at birth of both women and men. It increased from 51.8 years in 1968-71 to 64.4 years in 1996 for females, and from 52.9 years to 63.9 years for men during the same period (Table 8). It may be noted that the advantage of women in life expectation over men appeared only after 1981, implying for greater improvements in female mortality since the 1980s. 
Table 8

Gender Differences in Mortality Indicators

\begin{tabular}{lcr}
\hline Year & Female & Male \\
\hline Infant Mortality (per 1000 Births) & & \\
1980-85 & 94.9 & 100.9 \\
$1986-91$ & 79.7 & 98.5 \\
Life Expectancy (Years) & & \\
$1962-65$ & 48.7 & 52.4 \\
$1968-71$ & 51.8 & 52.9 \\
1981 & 57.7 & 57.6 \\
1986 & 60.1 & 59.9 \\
1991 & 62.1 & 62.0 \\
1996 & 64.6 & 63.9 \\
Maternal Mortality (per 100,00 Births) & & \\
1996 & 340.0 & - \\
\hline
\end{tabular}

Source: Same as Table 5. Pakistan Demographic and Health Survey 1990-91, National Institute of Population Studies. UNDP, 1998.

The maternal mortality rate, being an indicator of well being of women and mothers, is one of the highest in the region. Currently, a maternal mortality rate of 340 per 100,000 live births is reported for Pakistan [UNDP (1998)]. However, it varies by region and source as the National Health Survey has estimated it to be 288 per 100,000 live births, whereas Balochistan is reported to have the highest maternal mortality of 673 per 100,000 live births [PMRC (1998)]. More recently efforts to improve access to maternal and child health services, including the provision of lady health workers in the primary health care programme, especially in rural areas have been enhanced in all parts of the country. In this context, a major stride in health care delivery system including EPI, diarrhoeal and polio control programmes have reduced morbidity and mortality among infants.

The health status of population in general and women in particular is relatively poor compared with other countries in the region. The National Health Survey of 1994 reveals that anemia is high among people especially among children under five years of age and women in rural areas. The gender differentials in anemic population are distinct in all age groups, especially among 25-44 years olds where only 8.7 percent of men are reported as anemic compared with 37 percent of women in urban areas, and 19.5 percent of men compared with 37.3 percent of women in rural areas (Table 9). This marked difference in health status by gender reveals the vulnerable position of young women who are at much greater risks of illness and maternal deaths than men. 
Table 9

Gender Differences in Health Indicators: 1990-94

\begin{tabular}{lrrrrr}
\hline & \multicolumn{2}{c}{ Urban } & & \multicolumn{2}{c}{ Rural } \\
\cline { 2 - 3 } \cline { 5 - 6 } & Female & Male & & Female & Male \\
\hline Severe Malnutrition & & & & \\
$\quad$ Underweight & 13.7 & 8.7 & & 18.3 & 15.3 \\
$\quad$ Stunted & 13.9 & 12.0 & & 19.4 & 17.5 \\
Wasted & 2.0 & 1.5 & & 3.7 & 3.8 \\
Anemia (Children & & & & \\
$\quad$ under 5 Years) & & & & \\
1-2 & 68.8 & 62.8 & 69.4 & 68.1 \\
2-3 & 71.0 & 79.1 & 65.4 & 66.1 \\
3-4 & 52.1 & 40.6 & 48.6 & 53.3 \\
4-5 & 49.2 & 32.2 & 44.2 & 53.8 \\
Anemia (Population & & & & \\
5 Years and Above) & & & & \\
5-14 & 40.0 & 32.5 & 42.7 & 41.5 \\
15-24 & 33.1 & 15.3 & 37.5 & 24.6 \\
25-44 & 37.1 & 8.7 & 37.3 & 19.5 \\
45-65 & 24.2 & 17.3 & 32.9 & 26.8 \\
65 and above & 26.1 & 27.3 & 31.4 & 27.8 \\
\hline
\end{tabular}

Source: Same as Table 5.

The proportions of anemic children including both boys and girls under five years of age are also very high varying between 32 percent for 4-5 year old males in urban areas to 69 percent for 1-2 years old females in rural areas [PMRC (1998)]. The high anemic status of mothers adversely affects the health of their children which is further aggravated by severe malnutrition. The evidence from the National Health Survey shows that the proportion of severely malnourished children is higher for girls than boys in terms of being underweight, stunted or wasted (Table 9). This situation is to some extent reflective of the gender bias prevalent in the system where boys are given preference to girls in terms of food allocation health care and nurturing of children especially in poor and uneducated groups of households [Nayab (1998)]. A limited progress in women's health indicators are generally attributable to inadequate outreach of primary and reproductive health care services and insufficient development in other social sectors linked with health such as family planning, sanitation, nutrition and education. To deal with the adversity of health care services, it appears that inevitably the government will have to increase national spending on health and find alternative ways to reduce gender disparities in mortality and health against other pressing demands in the health sector. 


\section{Schooling and Work Participation}

As indicators of social and economic conditions, education and participation in formal employment are two major determinants of demographic change. Schooling is not only a basic human right but also a necessary condition for national development. Women's education, in particular, is instrumental in improving the quality of life within families and welfare of society in general, as it is widely accepted that progress for women's education is 'progress for all'.

With improvements in access to social and economic services, girls and women have benefited disproportionately from expanding education facilities and employment opportunities, especially in the formal sector. Because of unbalanced power relations perpetuated in the gender system in Pakistan, males are given first preference in terms of attaining education and participating in the labour market. As such, levels of literacy and school attainment have remained extremely low among females resulting large gender inequalities in all the regions. Recent estimates of literacy show that female literacy rate is still half of that of males in the year 1995-96 (31 percent vs 57 percent) even though there are indications of reduction in gender gap in education. The situation is somewhat better for urban females where 55 percent are literate compared with only 19 percent in rural areas. On the other hand, about half of rural (48.6 percent) and two-thirds of urban men (74.3 percent) are literate in 1995-96 (Table 10). While literacy rates for both men and women have gradually risen overtime, the situation of literacy and gender gap is still poor because 60 percent of population ( 55.5 million) is estimated as illiterate, and the number of illiterate women (31.7 million) is more than 60 percent of total illiterates [FBS (1998)]. This is a matter of great concern and merits attention for improving the situation of women.

Enrolment statistics have also shown positive trends at all levels of education. The ratio of female to male enrolment in schools and colleges has substantially improved between the years 1961-62 to 1996-97 (Table 11). A progressive increase in the sex ratio of enrolment clearly points towards lessening of gender inequities in education in recent years, especially at primary, and college level of education where females constitute more than 60 percent of male enrolments. At middle and secondary levels are reported as 58 and 52 percent respectively, of male enrolments in 1995-96.

The improvement in schooling is attributable to increased investments in public primary schools which targeted at least one school per village. The government has also introduced compulsory primary education with legislation in the provinces of Punjab and NWFP [Pakistan (1993)]. In addition, the private sector has made substantial contribution (an estimate of 30 to 40 percent) to the provision of schooling in Pakistan. As a result, schools have been brought closer to home, thereby inducing parents to send their children to school, especially their daughters. 
Table 10

Literacy Rates by Sex: 1961-1995-96 (for Population 10 Years and Above)

\begin{tabular}{lcccccccc}
\hline & \multicolumn{2}{c}{ All areas } & & \multicolumn{2}{c}{ Urban } & & \multicolumn{2}{c}{ Rural } \\
\cline { 2 - 3 } \cline { 8 - 9 } Year & Female & Male & & Female & Male & & Female & Male \\
\hline 1961 & 6.7 & 25.1 & & 21.3 & 44.9 & & 2.2 & 18.0 \\
1971 & 11.6 & 30.2 & & 30.9 & 49.9 & & 4.7 & 22.6 \\
1981 & 16.0 & 35.0 & & 37.3 & 55.3 & & 7.3 & 26.2 \\
$1995-96$ & 31.2 & 57.4 & & 55.2 & 74.3 & & 19.1 & 48.6 \\
\hline
\end{tabular}

Source: Economic Survey of Pakistan 1997-98, Ministry of Finance, Government of Pakistan.

Table 11

Sex Ratio of Enrolment by Educational Level (\% of Female Enrolment to Male)

\begin{tabular}{lccccc}
\hline Years & Primary & Middle & Secondary & College & University \\
\hline $1961-62$ & 26.8 & 19.4 & 20.8 & 24.1 & 22.7 \\
$1971-72$ & 35.8 & 25.5 & 25.7 & 35.8 & 28.4 \\
$1981-82$ & 49.7 & 35.2 & 32.1 & 49.7 & 21.7 \\
$1991-92$ & 52.9 & 40.4 & 37.0 & 51.9 & 23.9 \\
$1996-97$ & 68.3 & 58.6 & 52.4 & 61.8 & 28.9 \\
\hline
\end{tabular}

Source: Same as Table 5

Nevertheless, recent achievements and betterment in education reflect more of the urban environment, or an urban bias. It appears that the dynamism has been experienced mostly by urban residents where both women and men and, for practically all ages, have gained. But still the most favoured have been the young age cohorts between 10-29 years of age by the mid 1990s.

As the younger cohorts have become more educated, the share of the working age population $\left(10^{+}\right)$with little or no schooling has declined in Pakistan. However, the achievement and betterment of women in the labour market have not been as noteworthy as in education. Based on the 1996-97 Labour Force Survey estimates, about 70 percent of male population (10 years and above) are reported in the labour force compared with only 13.6 percent for females. As the formal sector has remained rather limited in Pakistan, work activities for females are concentrated mostly in the non-formal and agricultural sector. This means that nearly 86 percent of female work force is either involved in housekeeping activities or is in students category and not available for work. Despite large gender inequities in work participation, an increasing trend in women's activity rates is an encouraging sign.

It is generally known that women's activities are not counted as work, especially in rural areas where large number of women work on farms in various agricultural 
activities and in non-formal employment. If all those activities were included in the work category, it has been estimated that the improved activity rate for female would be 38.4 percent in 1996-97, 49.1 percent in rural and 17.1 percent in urban areas [FBS (1998)]. These figures indicate the extent to which female work is underestimated in rural areas where the majority of population resides (68 percent in 1998).

Changes in the labour force participation rates by age also indicate a typical pattern. The statistics obtained from labour force surveys indicate that during 1984-85 and 1996-97, activity rates show marked decline from 34.8 percent to 17.2 percent for males in the age group of 10-14 years and from 65.5 percent to 52.9 percent in the age group of 15-19 years (Table 12). This may be due to greater participation of boys in schooling and steps to discourage child work in recent years.

As the table shows, work participation rates for females have shown a gradual increase in all age groups between 1974-75 to 1996-97, even though these rates are likely to be an underestimate. Males have the highest participation rates between ages 20-64 years, whereas females' activity rates are almost evenly spread out between the same ages. The trends in activity rates reveal that women in Pakistan are at the lower end when compared with women from other countries in the region, and gender disparities persist in all age groups, reflecting their limited gains from the labour market as against men.

Table 12

Age-Specific Labour Force Participation Rate by Sex: Pakistan: 1974-75 to 1996-97

\begin{tabular}{|c|c|c|c|c|c|c|c|c|}
\hline \multirow[b]{2}{*}{ Age Groups } & \multicolumn{2}{|c|}{ 1974-75 } & \multicolumn{2}{|c|}{ 1984-85 } & \multicolumn{2}{|c|}{ 1994-95 } & \multicolumn{2}{|c|}{ 1996-97 } \\
\hline & Female & Male & Female & Male & Female & Male & Female & Male \\
\hline $10-14$ & 3.3 & 32.5 & 6.6 & 34.8 & 5.8 & 16.5 & 7.6 & 17.2 \\
\hline 15-19 & 5.3 & 64.7 & 8.5 & 65.5 & 9.6 & 51.1 & 13.1 & 52.9 \\
\hline $20-24$ & 6.6 & 88.4 & 8.7 & 89.9 & 11.7 & 85.5 & 15.1 & 85.1 \\
\hline $25-34$ & 7.9 & 96.9 & 10.4 & 98.6 & 12.8 & 97.2 & 13.8 & 97.3 \\
\hline 35-44 & 8.8 & 98.1 & 11.2 & 99.0 & 15.7 & 97.9 & 16.7 & 98.5 \\
\hline $45-54$ & 7.8 & 96.8 & 10.3 & 98.7 & 14.8 & 96.9 & 17.6 & 96.4 \\
\hline 55-64 & 6.1 & 91.9 & 5.7 & 94.8 & 15.2 & 91.5 & 17.3 & 85.1 \\
\hline $65+$ & 5.5 & $70.6^{*}$ & 4.0 & 67.1 & 9.2 & 62.6 & 10.4 & 53.4 \\
\hline 10 and above & 6.4 & 76.7 & 8.7 & 77.1 & 11.4 & 69.1 & 13.6 & 70.0 \\
\hline
\end{tabular}

Source: Economic Survey 1997-98, Ministry of Finance, Government of Pakistan.

Note: * 60 years and above taken. 


\section{CONCLUDING REMARKS}

Changes in the socio-demographic perspectives in Pakistan are suggestive of the fact that women have not only contributed but have also disproportionately gained from the development process. The analysis has shown that a transition in marital fertility behaviour has begun in recent years and a latent demand for limiting family size exists among all population strata. This finding has an important standing in the whole demographic scenario and needs to be implemented effectively to accelerate the pace of fertility decline in Pakistan in the foreseeable future.

On the mortality and health fronts, there are positive signs of improvements in infant mortality and life expectancy among both women and men, with greater advantage in favour of women since the 1980s. However, the heath status of mothers and children still remains poor with large proportions of anemic mothers and children who are also severely malnourished. In this regard, the health benefits of family planning and the relevance of reproductive health need to be recognised and made a part of the demographic concerns and development policies.

While women's education has risen relatively faster than men, gender inequities still exist especially in rural areas. Women's share in the labour market has increased slightly and wide gender gaps prevail in activity rates, especially in urban areas where men dominate in the formal sector.

All these factors are intertwined and mutually reinforcing, which have contributed to notable changes in the demographic front. The cumulative evidence shows that female education has strong negative association with completed fertility and desire for children, and a strong positive impact on contraceptive use, desire to space births, survival of infants, children and health care. Women's education also contributes to delaying age at marriage, greater husband-wife communication on family planning matters, better management of family resources and greater participation in paid employment. All these associations suggest that education can bring a qualitative shift in the lives of females and their families they live with.

As investment in education has not kept pace with rapidly increasing school-age population and low priority has been given to primary level education in the past, females have not been able to catch up fast with the past neglect. With high poverty levels and increased economic stress in recent years, many parents find it difficult to send their children to school, especially girls who are perceived with little economic and social benefits of schooling. Hence, policies and programmes to curtail gender inequities in education need to be geared up and given a priority against other pressing demands on the national budget.

As most of the population still resides in rural areas, statistics continue to be weighted in favour of reflecting conditions of the rural population. However, the estimates and analysis of demographic change indicate that dynamism has been, instead, 
experienced by urban residents representing nearly one third of total population. The majority of rural residents, particularly females, lag much behind and contribute to the continuation of gender inequities in various social and demographic indicators.

Viewing this assessment of gender inequities and social constraints for further change as a starting point, it appears that Pakistan needs to go a long way to turn things around. In this context among other things attitudinal and behavioural changes among people particularly men about gender sensitive issues merit attention. The overall situation raises some basic demographic question as to whether women, unable to prevent unwanted births for lack of family planning service delivery as well as limited autonomy and education, will end up with families greater than the desired ones. Because a large fraction of currently married women have unmet need for family planning, a substantial decline in fertility could occur if the constraining factors on contraceptive use are removed including husband's lack of support and approval.

While gender sensitivity has been incorporated into public sector programmes and documents, its implementation may still be questionable. The public sector and government apparatus remains strongly male dominated with little attention being given to differential needs and constraints faced by women and men. Recently, the government has initiated some programmes and subsidies including educational scholarship schemes for the poor and employment creation schemes for youth with no explicit gender based focus and share in the programmes. This suggests that gender dimensions of demographic and social change need to be emphasised in all policies and programmes in Pakistan for achieving a balanced and sustainable development.

\section{REFERENCES}

Abadian, S. (1996) Women’s Autonomy and its Impact on Fertility. World Development 24:12.

Afzal, M. (1998) Family Structure and the Elderly in Pakistan. Paper Prepared for the Regional Seminar on the Family and the Elderly. Bangkok: ESCAP.

Arnold, F. (1996) Son Preference in South Asia. Paper presented at the IUSSP Seminar on Comparative Perspectives on Fertility Transition in South Asia, Volume II. December, Rawalpindi.

Mahmood, N. (1996) Gender Differences in Fertility Desires and Son Preference in Pakistan: Implications for Reproductive Behaviour. Paper presented at the IUSSP Seminar on Comparative Perspectives on Fertility Transition in South Asia, Volume I. December, Rawalpindi.

Mahmood, N., and K. Ringheim (1997) Knowledge, Approval and Communication about Family Planning as Correlates of Desired Fertility Among Spouses in Pakistan. International Family Planning Perspectives 23: 122-129.

Ministry of Population Welfare and Population Council (1997) Pakistan Contraception Prevalence Survey 1994-95. Islamabad: Population Council. 
National Institute of Population Studies (NIPS) and Centre for Population Studies, London School of Hygiene and Tropical Medicine (1998) Pakistan Fertility and Family Planning Survey (PFFPS) 1996-97. Islamabad: NIPS.

Nayab, D. (1998) Fertility: Intentions and Behaviour. A Case Study of Two Villages in the Punjab, Pakistan. Unpublished masters dissertation.

Office of the Census Commissioner (1961) Population Census of Pakistan 1961. Karachi.

Pakistan Medical Research Council (1995) National Health Survey of Pakistan 1990-94. Islamabad.

Pakistan, Government of (1972) (1981) Census Report of Pakistan 1972, 1981. Islamabad: Population Census Organisation.

Pakistan, Government of (1986) Pakistan Contraception Prevalence Survey 198485. Islamabad: Ministry of Population Welfare Division

Pakistan, Government of (1993) Eighth Five-Year Plan. Islamabad: Planning and Development Division.

Pakistan, Government of (1995) Pakistan National Report. Fourth World Conference on Women, Beijing. Islamabad: Ministry of Women Development.

Pakistan, Government of (1998) Compendium on Gender Statistics Pakistan. Islamabad: Federal Bureau of Statistics.

Pakistan, Government of (1998) Economic Survey 1997-98. Islamabad: Finance Division.

Pakistan, Government of (1998) Provisional Results of Fifth Population and Housing Census 1998. Islamabad: Population Census Organisation.

Pakistan, Government of (n.d.) Labour Force Survey 1974-75, 1984-85, 1994-95, 1996-97. Islamabad: Statistics Division.

Population Council (1997) The Gap between Reproductive Intentions and Behaviour: A Study of Punjabi Men and Women. Islamabad: Population Council.

Sathar, Z. A. (1996) Women's Schooling and Autonomy as Factors in Fertility Change in Pakistan: Some Empirical Evidence. In R. Jeffery and A. M. Basu (eds) Girls' Schooling, Women's Autonomy and Fertility Change in South Asia. New Delhi: Sage Publication.

Sathar, Z., and S. Kazi (1997) Women's Autonomy, Livelihood, and Fertility: A Study of Rural Punjab. Pakistan Institute of Development Economics, Islamabad.

United Nation Development Program (UNDP) (1998) Human Development Report 1998. New York: Oxford University Press.

United Nations (1995) Population and Development. Programme of Action adopted at the International Conference on Population and Development (ICPD), Cairo, 5-13 September, 1994. Department for Economic and Social Information and Policy Analysis. 